\title{
Effects of bezafibrate on lipid and glucose metabolism in dyslipidemic patients with diabetes: the J-BENEFIT study
}

\author{
Tamio Teramoto ${ }^{1 *}$, Kohji Shirai ${ }^{2}$, Hiroyuki Daida ${ }^{3}$ and Nobuhiro Yamada ${ }^{4}$
}

\begin{abstract}
Background: The hypoglycemic effect of bezafibrate is well established, but administration to a large population of patients with diabetes has not been reported. We investigated glycemic control, relationship between lipid metabolism and $\mathrm{HbA1c}$, and safety in diabetic patients treated with bezafibrate.

Methods: A prospective, observational analysis was conducted on 6,407 dyslipidemic patients suffering from diabetes or hyperglycemia who had not received bezafibrate previously. Subanalyses were performed on the concomitant use of diabetes drugs, diabetes duration, and baseline HbA1c levels.

Results: Bezafibrate significantly decreased HbA1c irrespective of concomitant use of other diabetes drugs in a baseline-HbA1c-dependent manner, with patients with a shorter diabetes duration showing a greater decrease in $\mathrm{HbA1c}$ than those with longer-term disease. The rate of change in triglyceride levels was significantly associated with that in HbA1c. Adverse drug reactions occurred in 306 patients (5.1\%), of which reactions in 289 were not severe (94.4\%).

Conclusions: Bezafibrate significantly improved HbA1c in patients with diabetes given individualized treatment. Bezafibrate may offer clinicians an improved modality for the amelioration of disease course and improvement of outcome in these patients.
\end{abstract}

Keywords: Bezafibrate, Diabetes, Triglyceride, HbA1c

\section{Background}

The prevalence of patients with or at risk of type 2 diabetes is increasing rapidly in Japan, which is in the top 10 of Asian countries with respect to population diagnosed with diabetes and impaired glucose tolerance [1]. Hyperglycemia in patients with type 2 diabetes places them at significant risk for cardiovascular events and other diabetic complications [2], as shown for example by the United Kingdom Prospective Diabetes Study (UKPDS 35), which demonstrated a strong association between the risk of diabetic complications and hyperglycemia [3]. Patients with type 2 diabetes also tend to have higher triglyceride (TG) and lower high-density lipoprotein cholesterol (HDL-C) levels than non-

\footnotetext{
* Correspondence: ttera@med.teikyo-u.ac.jp

'Department of Internal Medicine, Teikyo University School of Medicine, 2-

11-1 Kaga, Itabashi-ku, Tokyo, Japan

Full list of author information is available at the end of the article
}

diabetics [4]; for example, Lehto et al. reported that the simultaneous presence of hyperglycemia with either low HDL-C or high TG levels increased the risk of cardiovascular events up to three-fold in patients with type 2 diabetes [5]. Effective treatment of type 2 diabetes must therefore involve the management of blood glucose and lipids, including TG and HDL-C levels.

The ability of bezafibrate to reduce TG, cholesterol, and blood glucose levels in patients with diabetes was first reported over 30 years ago [6,7], and the drug has become widely used for treating dyslipidemia, particularly to improve TG and HDL-C levels [reviewed in [8]]. Moreover, previous research has shown that bezafibrate functions as an agonist of PPAR nuclear transcription factors, which play an important role in glucose and lipid metabolism [9-13]. Although as indicated above, bezafibrate improves lipid and glucose metabolism

\section{Ciomed Central}


[14-17], we are unaware of any detailed investigation of its effects in a large cohort of patients with diabetes.

Here, we conducted a 24-week prospective observational study of bezafibrate in the treatment of dyslipidemic patients with diabetes, designated the "Iapan BEzafibrate cliNical EFfectIveness and Tolerability (JBENEFIT)" study.

\section{Methods}

\section{Subjects}

This prospective observational study of dyslipidemic patients with diabetes was conducted as post-marketing surveillance to evaluate the efficacy and safety of bezafibrate therapy. We included only those patients who met all inclusion criteria and did not have any conditions listed in the exclusion criteria. The inclusion criteria were as follows:

1. No prior administration of bezafibrate

2. Serum TG $\geq 1.7 \mathrm{mmol} / \mathrm{l}(\geq 150 \mathrm{mg} / \mathrm{dl})$ and/or serum total cholesterol $(\mathrm{TC}) \geq 5.7 \mathrm{mmol} / \mathrm{l}(\geq 220 \mathrm{mg} / \mathrm{dl})$

3. Diagnosis of diabetes or most recent fasting blood glucose $(\mathrm{FBG}) \geq 6.1 \mathrm{mmol} / \mathrm{l}(\geq 110 \mathrm{mg} / \mathrm{dl})$

The exclusion criteria were as follows:

1. Undergoing dialysis treatment

2. Severe renal disease (on dialysis or in renal failure)

3. Blood creatinine $\geq 152.5 \mu \mathrm{mol} / \mathrm{l}(\geq 2.0 \mathrm{mg} / \mathrm{dl})$

4. History of bezafibrate hypersensitivity

5. Pregnant or possibly pregnant

Subjects were enrolled by centralized registration from June 2003 to March 2005, and the study was conducted from June 2003 to September 2005. Patients were administered $400 \mathrm{mg} /$ day bezafibrate for 24 weeks. We evaluated the efficacy and safety of bezafibrate in each analysis group. Safety was evaluated in all patients whose case report forms were collected, except those with protocol violations or insufficient data for safety analysis. Efficacy was evaluated in all patients except those with protocol noncompliance or insufficient data for efficacy analysis from safety analysis group. Efficacy endpoints included lipid metabolism parameters such as TG, TC, low-density cholesterol (LDL-C), HDL-C, nonHDL-C, and TG/HDL ratio and glucose metabolism parameters such as FBG, HbA1c, and homeostasis model assessment insulin resistance (HOMA-R). Laboratory tests were performed at each of the 1,066 institutions. Efficacy endpoints were assessed at baseline and after 24 weeks of treatment. For observations $<24$ weeks, efficacy endpoints were assessed at the last measurement (12 weeks treatment onward). LDL-C was calculated by the Friedwald formula [18] in patients with $\mathrm{TG}<4.4 \mathrm{mmol} / \mathrm{l}$. The TG/HDL-C ratio and non-HDL$\mathrm{C}$ were calculated using TC, TG, and HDL-C values. HbA1c was measured according to the Japan Diabetes
Society's (JDS) method [19] and then converted to the corresponding National Glycohemoglobin Standardization Program (NGSP) value. HbA1c value was estimated as an NGSP-equivalent value calculated with the following formula:

$$
\text { HbA1c }(\text { NGSP })=\text { HbA1c }(\text { JDS })+0.4
$$

considering the relational expression of HbA1c (JDS) measured with the previous Japanese standard substance and methods and HbA1c (NGSP) [19]. Safety endpoints were evaluated as the incidence of adverse drug reaction (ADR), and included laboratory value abnormalities for which an association with bezafibrate could not be ruled out.

\section{Statistical analysis}

All statistical analyses were performed using SAS version 8.12 (SAS Institute). A paired $t$-test was used to compare endpoints after treatment versus baseline with two-tailed significance set at 5\%. ANOVA was performed to evaluate linear trends among subgroups classified by baseline HbA1c levels and duration of diabetes. Univariate and stepwise multivariate regression analyses were performed to evaluate independent predictors of the change in HbA1c. The explanatory variables examined were patient age, sex, baseline BMI, baseline $\mathrm{HbA1c}$, administration of diabetes drugs during the study, duration of diabetes, and rate of change of each lipid including TC, LDL-C, TG, and HDL-C. This study was conducted in compliance with good post-marketing surveillance practice and the guidelines on the methods for surveillance of the results of prescription drug use issued by the Ministry of Health, Labour, and Welfare, Japan.

\section{Results}

Patients

We enrolled 6,449 patients and collected 6,407 case report forms. Safety was evaluated in 5,978 patients. Patients were excluded from safety analysis for the following reasons, namely 1) protocol violation: some patients did not receive bezafibrate $(\mathrm{n}=13)$, had a delay in enrollment $(n=292)$, and had a history of bezafibrate treatment $(\mathrm{n}=20)$; and 2) insufficient data for safety analysis $(n=104)$. A total of 429 of 6407 patients were excluded. Patients were excluded from efficacy analysis for the following reasons: 1) protocol violation: patients had neither TG $\geq 1.7 \mathrm{mmol} / \mathrm{l}$ nor $\mathrm{TC} \geq 5.7 \mathrm{mmol} / \mathrm{l}(\mathrm{n}=$ 920 ), or patients had neither diabetes nor FBG $\geq 6.1$ $\mathrm{mmol} / \mathrm{l}$ ( $\mathrm{n}=653$, overlapping); 2 ) insufficient data for efficacy analysis: dose or duration of bezafibrate unknown ( $\mathrm{n}=86)$; data incomplete for baseline or after administration for any one of TC, TG, and HbA1c ( $\mathrm{n}=$ 
2,387); pretreatment for hyperlipidemia unknown or pretreatment with diabetes drugs, or both $(n=783)$; unknown concomitant drug for treating hyperlipidemia or unknown diabetes drug $(\mathrm{n}=6)$; or both (these cases overlapped, resulting in 2,662 cases being excluded from safety analyses).

Patients' backgrounds in the efficacy analysis group are shown in Table 1 . The number of patients with diabetes was 3,312 (99.9\%), of whom 3,235 (97.6\%) were diagnosed with type 2 diabetes. Mean duration of diabetes was $6.6 \pm 5.9$ years. A total of $602(18.2 \%)$ and 1,977 (59.6\%) patients had been previously treated for dyslipidemia and diabetes, respectively. Medication characteristics of the efficacy analysis group showed that while most patients $(3,149 ; 95.0 \%)$ were treated for dyslipidemia with bezafibrate alone, 167 patients $(5.0 \%)$ took other lipid-lowering drugs concurrently (Table 2).

Table 1 Characteristics of patients in the efficacy analysis group

\begin{tabular}{|c|c|}
\hline Characteristics of Patients & $\mathrm{n}(\%)$ or mean $\pm \mathrm{SD}$ \\
\hline Number & 3316 \\
\hline \multicolumn{2}{|l|}{ Entry category } \\
\hline Type 1 diabetes, n/\% & $40(1.2 \%)$ \\
\hline Type 2 diabetes, $\mathrm{n} / \%$ & $3235(97.6 \%)$ \\
\hline Diabetes (diagnosis unknown), n/\% & $37(1.1 \%)$ \\
\hline $\mathrm{FBG} \geq 6.1[\mathrm{mmol} / \mathrm{l}], \mathrm{n} / \%$ & $4(0.1 \%)$ \\
\hline Outpatients, n/\% & $3212(96.9 \%)$ \\
\hline Men, $\mathrm{n} / \%$ & $2074(62.5 \%)$ \\
\hline Age, mean/SD & $61.0 \pm 12.0$ \\
\hline$\geq 65$ yeas, $n / \%$ & $1400(42.2 \%)$ \\
\hline BMI $\left(\mathrm{kg} / \mathrm{m}^{2}\right)$, mean $/ \mathrm{SD}$ & $25.7 \pm 3.7$ \\
\hline Smoking, n/\% & $825(24.9 \%)$ \\
\hline Alcohol consumption, n/\% & $1129(34.0 \%)$ \\
\hline Complication, n/\% & $2397(72.3 \%)$ \\
\hline Hepatic disease, n/\% & $339(10.2 \%)$ \\
\hline Kidney disease, n/\% & $51(1.5 \%)$ \\
\hline Hypertension, $\mathrm{n} / \%$ & $1614(48.7 \%)$ \\
\hline Heart disease, n/\% & $325(9.8 \%)$ \\
\hline Duration of hyperlipidemia (years), mean/SD & $4.7 \pm 4.3$ \\
\hline Duration of diabetes (years), mean/SD & $6.6 \pm 5.9$ \\
\hline Previous treatment of hyperlipidemia, n/\% & $602(18.2 \%)$ \\
\hline Previous treatment of diabetes, $\mathrm{n} / \%$ & $1977(59.6 \%)$ \\
\hline Total cholesterol (mmol/l), mean/SD & $5.76 \pm 1.03$ \\
\hline LDL cholesterol (mmol/l), mean/SD & $3.19 \pm 0.95$ \\
\hline HDL cholesterol $(\mathrm{mmol} / \mathrm{l})$, mean/SD & $1.18 \pm 0.33$ \\
\hline $\mathrm{TG}(\mathrm{mmol} / \mathrm{l})$, mean/SD & $3.72 \pm 2.45$ \\
\hline HbA1c (\%), mean/SD & $7.69 \pm 1.52$ \\
\hline FBG $(\mathrm{mmol} / \mathrm{l})$, mean/SD & $9.01 \pm 3.49$ \\
\hline
\end{tabular}

Table 2 Drug treatment

\begin{tabular}{|c|c|c|}
\hline & Medication & n (\%) \\
\hline Total number of patients & & 3316 \\
\hline \multicolumn{3}{|c|}{$\begin{array}{l}\text { Concomitant administration of lipid-lowering drug during } \\
\text { the study }\end{array}$} \\
\hline No concomitant drug & & $\begin{array}{c}3149 \\
(95.0 \%)\end{array}$ \\
\hline Concomitant administration & & $167(5.0 \%)$ \\
\hline statin & & $119(3.6 \%)$ \\
\hline others & & $48(1.4 \%)$ \\
\hline \multicolumn{3}{|c|}{ diabetes drug administration before and during the study } \\
\hline -Before- & -During- & \\
\hline Not taken & Not taken & $818(24.7 \%)$ \\
\hline Not taken & Taken & $521(15.7 \%)$ \\
\hline Taken & Not taken & $106(3.2 \%)$ \\
\hline Taken & Taken & $\begin{array}{c}1871 \\
(56.4 \%)\end{array}$ \\
\hline No concomitant diabetes drug during & udy & $924(27.9 \%)$ \\
\hline $\begin{array}{l}\text { Concomitant treatment with diabetes } \\
\text { study }\end{array}$ & luring the & $\begin{array}{c}2392 \\
(72.1 \%) \\
\end{array}$ \\
\hline \multicolumn{3}{|l|}{ Single treatment with: } \\
\hline Sulfonylurea & & $732(22.1 \%)$ \\
\hline Glinide & & $188(5.7 \%)$ \\
\hline Alpha-glucosidase inhibitor & & $169(5.1 \%)$ \\
\hline Biguanide & & $93(2.8 \%)$ \\
\hline Thiazolidine & & $49(1.5 \%)$ \\
\hline Insulin & & $156(4.7 \%)$ \\
\hline \multicolumn{3}{|l|}{ Combination therapies: } \\
\hline $\begin{array}{l}\text { Sulfonylurea + alpha-glucosidase } \\
\text { inhibitor }\end{array}$ & & $229(6.9 \%)$ \\
\hline Sulfonylurea + biguanide & & $212(6.4 \%)$ \\
\hline Sulfonylurea + thiazolidine & & $91(2.7 \%)$ \\
\hline Other & & $473(14.3 \%)$ \\
\hline
\end{tabular}

All patients were classified into four subgroups according to diabetes drug administration before and during the study as follows: diabetes drug not taken before or during the study ( $\mathrm{n}=818,24.7 \%)$, taken only during the study ( $\mathrm{n}=521,15.7 \%)$, taken only before the study $(\mathrm{n}=106,3.2 \%)$ and taken before and during the study ( $\mathrm{n}=1,871,56.4 \%$ ). Thus, a diabetes drug was taken by 2,392 patients $(72.1 \%)$ during the study. The most frequently used diabetes drug regimen was single administration of sulfonylureas (22.1\%) followed by combined use of sulfonylureas and an $\alpha$-glucosidase inhibitor $(6.9 \%)$ (Table 2). The number of patients receiving both monotherapy and combination use of diabetes drugs was as follows: sulfonylureas ( $\mathrm{n}=1,505$, $45.4 \%)$, glinides $(\mathrm{n}=341,10.3 \%), \alpha$-glucosidase inhibitor $(\mathrm{n}=685,20.7 \%)$, biguanide $(\mathrm{n}=550,16.6 \%)$, thiazolidine $(\mathrm{n}=287,8.7 \%)$, and insulin $(\mathrm{n}=284,8.6 \%)$ (data not shown). All of 3,316 patients took bezafibrate at 
least 6 weeks, of whom 3,299 (99.5\%) took the drug for at least 12 weeks and $17(0.5 \%)$ for at least six weeks. The dose of bezafibrate was $400 \mathrm{mg} /$ day in 2,728 (82.3\%) patients and $200 \mathrm{mg} /$ day in $472(14.2 \%)$.

\section{Effect of bezafibrate on blood lipid and glucose levels}

Table 3 presents the changes in lipid and glucose parameters at baseline and after bezafibrate administration. All lipid values except LDL-C improved significantly compared with baseline values. Significant decreases from baseline were observed for TC, TG, non-HDL-C, and TG/HDL-C ratio; in contrast, a significant increase was observed in HDL-C. Although LDL-C levels decreased significantly in patients with LDL-C $\geq 3.6$ $\mathrm{mmol} / \mathrm{l}$ at baseline $(\mathrm{n}=737)$, they increased significantly in those with LDL-C $<3.6 \mathrm{mmol} / \mathrm{l}$ at baseline $(\mathrm{n}=$ 1,489). Thus, LDL-C levels increased significantly overall. Moreover, HbA1c, FBG, and HOMA-R levels decreased significantly.

\section{Effect of bezafibrate on blood glucose levels - subgroup analysis}

Table 4 summarizes the changes in HbA1c concentrations after treatment, classified according to use of diabetes drug and baseline $\mathrm{HbA} 1 \mathrm{c}$ levels. We analyzed 2,086 patients whose baseline HbA1c values were $\geq 7.0 \%$. $\mathrm{HbA} 1 \mathrm{c}$ levels decreased significantly by $-0.76 \%$ from baseline in all patients. This change was greater in patients whose baseline HbA1c levels were higher. The trend analysis showed significant differences between the HbA1c-subgroups. Similar results were observed in all medication subgroups classified by diabetes drug administration before and during the study.

There were 1,464 patients for which we could determine the change in HbA1c levels as a function of duration of diabetes (Table 5). HbA1c levels significantly decreased in all diabetes-duration subgroups, most strongly in the subgroup with diabetes for $<1$ year. Trend analysis showed significant differences between the diabetes-duration subgroups. Similar results were also observed in the medication subgroup of patients who were not administrated diabetes drug before or during the study.

We also analyzed HbA1c levels according to concomitant use of a single diabetes drug during the study. Changes in HbA1c levels for each drug were as follows: sulfonylureas, $\mathrm{n}=536,-0.84 \%, \mathrm{p}<0.001$; glinides, $\mathrm{n}=$ $125,-0.82 \%, \mathrm{p}<0.001$; alpha glucosidase inhibitor, $\mathrm{n}=$ $70,-0.66 \%, \mathrm{p}<0.001$; biguanide, $\mathrm{n}=239,-0.73 \%, \mathrm{p}<$ 0.001; thiazolidine, $\mathrm{n}=28,-0.64 \%, \mathrm{p}=0.004$; insulin: $\mathrm{n}$ $=130,-0.59 \%, \mathrm{p}<0.001$. Each regimen showed a significant decrease in HbA1c. There were no significant differences between any of the regimens $(p=0.363)$ (data not shown).

\section{Factors influencing $\mathrm{HbA1c}$ levels}

We conducted univariate and multivariate regression analyses to evaluate the influence of bezafibrate on HbA1c levels. For initial univariate analysis of 1,854 patients, the difference in HbA1c levels was as an objective variable. Explanatory variables were patient age, sex, baseline BMI, baseline HbA1c level, diabetes-drug administration during the study, duration of diabetes, and rate of change in levels of each lipid (TC, LDL-C, TG, and HDL-C). Based on these results, baseline BMI, baseline $\mathrm{HbA1c}$, diabetes-drug administration, rate of change in TG, HDL-C, and TC were found to be significant variables.

We next performed multivariate regression analysis using these variables and found that the estimated influence rate per unit change in each variable on HbA1c was as follows: baseline HbA1c, -0.489 ; baseline BMI, 0.016; diabetes-drug administration, 0.176 ; rate of change in TG, 0.004; and rate of change in TC, 0.005 . The rate of change in HDL-C was not a significant variable (Table 6). Further, the average rates of change in TG and TC for all subjects at 24 weeks were $-45.4 \%$ and $-5.4 \%$, respectively (Table 3 ). When the rate of change in

Table 3 Analysis of lipid and glycemic parameters

\begin{tabular}{|c|c|c|c|c|c|}
\hline & $\mathrm{n}$ & Baseline mean \pm SD & After administration mean \pm SD & Difference & Percentage \\
\hline TC $(\mathrm{mmol} / \mathrm{L})$ & 3316 & $5.76 \pm 1,03$ & $5.45 \pm 0.94$ & $-0.31 \pm 1.00 \S$ & $-5.4 \%$ \\
\hline $\mathrm{LDL}-\mathrm{C}(\mathrm{mmol} / \mathrm{L})$ & 2226 & $3.19 \pm 0.95$ & $3.25 \pm 0.81$ & $0.05 \pm 0.90 \neq$ & $1.6 \%$ \\
\hline $\mathrm{TG}(\mathrm{mmol} / \mathrm{L})$ & 3316 & $3.72 \pm 2.45$ & $2.03 \pm 1.50$ & $-1.69 \pm 2.08 \S$ & $-45.4 \%$ \\
\hline $\mathrm{HDL}-\mathrm{C}(\mathrm{mmol} / \mathrm{L})$ & 2818 & $1.18 \pm 0.32$ & $1.34 \pm 0.35$ & $0.17 \pm 0.25 \S$ & $14.0 \%$ \\
\hline non-HDL-C (mmol/L) & 2818 & $4.57 \pm 0.99$ & $4.11 \pm 0.96$ & $-0.46 \pm 0.09 \S$ & $-10.1 \%$ \\
\hline $\mathrm{TG} / \mathrm{HDL}$ & 1818 & $3.49 \pm 2.75$ & $1.70 \pm 1.59$ & $-1.79 \pm 2.31 \S$ & $-51.3 \%$ \\
\hline $\mathrm{HbA1c}(\%)$ & 3316 & $7.69 \pm 1.52$ & $7.22 \pm 1.28$ & $-0.47 \pm 1.21 \S$ & $-6.2 \%$ \\
\hline FBG $(\mathrm{mmol} / \mathrm{L})$ & 2387 & $9.00 \pm 3.46$ & $7.81 \pm 2.89$ & $-1.19 \pm 3.33 \S$ & $-13.2 \%$ \\
\hline HOMA-R & 102 & $4.46 \pm 4.91$ & $3.38 \pm 3.83$ & $-1.08 \pm 4.78+$ & $-24.3 \%$ \\
\hline
\end{tabular}

"Difference" indicates the value for the change from baseline. "Percentage" indicates rate of change from baseline. A paired $t$-test was used to assess statistically significant differences from baseline for each group. Symbols for $p$ values in this and the tables that follow: $\dagger: p<0.05, \neq: p<0.01, \S: p<0.001$ 
Table $4 \mathrm{HbA1c}$ levels as a function of concomitant diabetes drug use and baseline HbA1c levels

\begin{tabular}{|c|c|c|c|c|c|c|}
\hline Medication classification & HbA1c classification & $\mathrm{n}$ & Baseline mean \pm SD & After administration mean \pm SD & Differer & nce \\
\hline \multirow[t]{4}{*}{ All patients } & Total & 2086 & $8.46 \pm 1.40$ & $7.71 \pm 1.31$ & $-0.76 \pm 1.38 \S$ & \multirow{4}{*}{$p<0.001$} \\
\hline & $7-8 \%$ & 1010 & $7.46 \pm 0.29$ & $7.20 \pm 0.77$ & $-0.25 \pm 0.74 \S$ & \\
\hline & $8-9 \%$ & 555 & $8.44 \pm 0.28$ & $7.75 \pm 1.02$ & $-0.69 \pm 1.01 \S$ & \\
\hline & $\geq 9 \%$ & 521 & $10.45 \pm 1.29$ & $8.64 \pm 1.79$ & $-1.81 \pm 1.97 \S$ & \\
\hline Diabetes drug use & Subtotal & 254 & $7.84 \pm 1.04$ & $7.28 \pm 1.00$ & $-0.56 \pm 1.06 \S$ & \\
\hline $\begin{array}{l}\text { Before study: not taken } \\
\qquad \&\end{array}$ & $7-8 \%$ & 186 & $7.38 \pm 0.26$ & $7.06 \pm 0.67$ & $-0.32 \pm 0.66$ & $p<0.001$ \\
\hline \multirow[t]{2}{*}{ During study: not taken } & $8-9 \%$ & 46 & $8.38 \pm 0.26$ & $7.64 \pm 1.08$ & $-0.74 \pm 1,03 \S$ & \\
\hline & $\geq 9 \%$ & 22 & $10.64 \pm 1.24$ & $8.48 \pm 1.85$ & $-2.16 \pm 2.03 \S$ & \\
\hline & Subtotal & 397 & $8.89 \pm 1.66$ & $7.42 \pm 1.36$ & $-1.47 \pm 1.88 \S$ & \multirow{4}{*}{$p<0.001$} \\
\hline $\begin{array}{l}\text { Before study: not taken } \\
\qquad \&\end{array}$ & $7-8 \%$ & 147 & $7.46 \pm 0.29$ & $7.06 \pm 0.85$ & $-0.39 \pm 0.86 \S$ & \\
\hline \multirow[t]{2}{*}{ During study: taken } & $8-9 \%$ & 109 & $8.45 \pm 0.29$ & $7.31 \pm 0.96$ & $-1.15 \pm 0.97 \S$ & \\
\hline & $\geq 9 \%$ & 141 & $10.73 \pm 1.40$ & $7.89 \pm 1.84$ & $-2.84 \pm 2.30 \S$ & \\
\hline & Subtotal & 59 & $8.26 \pm 1.33$ & $7.79 \pm 1.23$ & $-0.47 \pm 1.10 \neq$ & \multirow{4}{*}{$p=0.003$} \\
\hline $\begin{array}{l}\text { Before study: taken } \\
\&\end{array}$ & $7-8 \%$ & 34 & $7.48 \pm 0.28$ & $7.26 \pm 0.83$ & $-0.22 \pm 0.85$ & \\
\hline \multirow[t]{3}{*}{ During study: not taken } & $8-9 \%$ & 14 & $8.50 \pm 0.28$ & $8.09 \pm 1.03$ & $-0.41 \pm 0.93$ & \\
\hline & $\geq 9 \%$ & 11 & $10.38 \pm 1.67$ & $9.05 \pm 1.51$ & $-1.32 \pm 1.59+$ & \\
\hline & Subtotal & 1376 & $8.46 \pm 1.33$ & $7.86 \pm 1.31$ & $-0.60 \pm 1.20 \S$ & \multirow{4}{*}{$p<0.001$} \\
\hline $\begin{array}{l}\text { Before study: taken } \\
\&\end{array}$ & $7-8 \%$ & 643 & $7.48 \pm 0.29$ & $7.28 \pm 0.76$ & $-0.20 \pm 0.73 \S$ & \\
\hline \multirow[t]{2}{*}{ During study: taken } & $8-9 \%$ & 386 & $8.44 \pm 0.27$ & $7.88 \pm 1.00$ & $-0.56 \pm 0.98 \S$ & \\
\hline & $\geq 9 \%$ & 347 & $10.32 \pm 1.22$ & $8.94 \pm 1.69$ & $-1.38 \pm 1.66 \S$ & \\
\hline
\end{tabular}

Baseline HbA1c levels for 2086 patients were $\geq 7.0 \%$. A paired $t$-test was used to assess statistically significant differences from baseline for each group. P values were determined by ANOVA to assess statistically differences from baseline among baseline HbA1c-subgroup

each lipid was considered, their estimated influences on altering HbA1c levels were $-0.182 \%$ and $-0.027 \%$, respectively. Next, we analyzed the relationship between rate of change in TG and amount of change in HbAlc in 3,316 patients (Figure 1). Irrespective of diabetes drug administration during the study, a strong positive relationship was observed between the rates of change in TG and amount of change in HbA1c levels.

\section{Safety}

Drug safety was assessed for 5,978 patients. ADRs were experienced by 306 patients (5.1\%) (Table 7). The most common ADRs were increased blood creatine phosphokinase $(0.8 \%)$, blood creatinine $(0.8 \%)$, blood urea $(0.5 \%)$, renal impairment $(0.3 \%)$, and aspartate aminotransferase $(0.3 \%)$. Severe ADRs were experienced by 17 patients $(0.28 \%)$ and mainly included stroke $(\mathrm{n}=2,0.03 \%)$, renal

Table 5 HbA1c-levels as a function of the duration of diabetes

\begin{tabular}{cccccc}
\hline $\begin{array}{c}\text { Medication } \\
\text { classification }\end{array}$ & $\begin{array}{c}\text { Duration of diabetes } \\
\text { classification }\end{array}$ & $\mathbf{n}$ & $\begin{array}{c}\text { Baseline maen } \pm \\
\text { SD }\end{array}$ & $\begin{array}{c}\text { After administration mean } \pm \\
\text { SD }\end{array}$ & Difference mean \pm SD \\
\hline All cases & Total & 1464 & $8.44 \pm 1.34$ & $7.76 \pm 1.29$ & $-0.68 \pm 1.34 \S$ \\
& $<1$ year & 70 & $8.65 \pm 1.63$ & $7.04 \pm 1.08$ & $-1.60 \pm 1.82 \S$ \\
& & & & $p=$ \\
& $1-5$ years & 503 & $8.38 \pm 1.35$ & $7.69 \pm 1.38$ & $-0.69 \pm 1.50 \S$ \\
& $5-10$ years & 432 & $8.37 \pm 1.25$ & $7.81 \pm 1.22$ & $-0.56 \pm 1.02 \S$ \\
& $\geq 10$ years & 459 & $8.56 \pm 1.36$ & $7.90 \pm 1.25$ & $-0.66 \pm 1.27 \S$ \\
\hline Diabetes drug use & Subtotal & 147 & $7.81 \pm 0.95$ & $7.33 \pm 1.05$ & $-0.47 \pm 1.00 \S$ \\
Before study: not taken & $<1$ year & 14 & $7.72 \pm 0.89$ & $6.52 \pm 0.75$ & $-1.20 \pm 1.31 \neq$ \\
\& & & & & & $p=$ \\
During study: not taken & $1-5$ years & 75 & $7.73 \pm 0.78$ & $7.45 \pm 1.08$ & $-0.28 \pm 0.88 \neq$ \\
& $5-10$ years & 38 & $7.85 \pm 1.15$ & $7.38 \pm 1.13$ & $-0.47 \pm 0.97 \neq$ \\
\hline
\end{tabular}


Table 6 Stepwise multiple regression analysis of the change in $\mathrm{HbA1c}$ levels in relation to explanatory variables

\begin{tabular}{ccccc}
\hline Explanatory variable & $\begin{array}{c}\text { Regression } \\
\text { coefficient }\end{array}$ & SE & $\begin{array}{c}t- \\
\text { value }\end{array}$ & $\begin{array}{c}\text { p- } \\
\text { value }\end{array}$ \\
\hline Baseline HbA1c (\%) & -0.489 & 0.015 & -31.79 & $<$ \\
& 0.016 & 0.006 & 2.70 & 0.007 \\
Baseline BMI (kg/m²) & 0.176 & 0.049 & 3.59 & $<$ \\
Diabetes drug & 0.004 & 0.001 & 6.34 & $<$ \\
administration & 0.005 & 0.001 & 4.13 & $<$ \\
$\begin{array}{c}\text { Change rate in TG (\%) } \\
\text { Change rate in TC (\%) }\end{array}$ & -0.002 & 0.001 & -1.72 & 0.001 \\
$\begin{array}{c}\text { Change rate in HDL-C } \\
\text { (\%) }\end{array}$ & & & & \\
\hline
\end{tabular}

$\mathrm{R}^{2}=0.3884$. Each estimated value indicates the influence in $\mathrm{HbA1C}$ per 1 unit change in each variable. The estimated values of diabetes-drug administration indicate the rates of influence in patients with and without drug

impairment $(\mathrm{n}=2,0.03 \%)$, elevated blood urea nitrogen $(\mathrm{n}=2,0.03 \%)$, abnormal hepatic function $(\mathrm{n}=1$, $0.02 \%)$, pneumonia $(\mathrm{n}=1,0.02 \%)$, rhabdomyolysis $(\mathrm{n}=$ $1,0.02 \%)$, hypoglycemia $(\mathrm{n}=1,0.02 \%)$, and others. ADR rate increased slightly in patients concurrently taking diabetes drugs ( $4.3 \%$ not taking vs. $5.6 \%$ taking), but no apparent clinical differences were observed. One hypoglycemia case occurred in a patient concurrently taking a diabetes drug. Rhabdomyolysis was observed in five patients, four of whom were treated with a diabetes drug. No ADRs were observed that could be unequivocally ascribed to concurrent diabetes drug use.

\section{Discussion}

In this study, we showed that treatment with bezafibrate significantly reduced $\mathrm{HbA} 1 \mathrm{c}$ levels in patients with diabetes complicated by dyslipidemia. This effect was observed in a baseline HbA1c-dependent manner, regardless of concurrent use of diabetes drugs. Patients with a shorter duration of diabetes showed greater decreases in HbA1c levels. Further, the rate of change in triglyceride levels was related to changes in $\mathrm{HbA} 1 \mathrm{c}$ levels. Adverse drug reactions occurred in 306 patients (5.1\%), but these were not severe in 289 (94.4\%). Taken together, these results suggest that bezafibrate, which improves both lipid and blood glucose metabolism, should be considered suitable for the treatment of dyslipidemia in patients with diabetes.

The importance of the rigorous control of glycemia in diabetes is confirmed by the striking findings that a $1 \%$ reduction in HbA1c level is associated with a $21 \%$ decrease in risk of death related to diabetes [3], and that a $1-\mathrm{mmol} / \mathrm{l}$ increase in TG level is associated with a $32 \%$ increased risk of a cardiovascular event [20]. HbA1c correlates significantly with both TG and HDL$\mathrm{C}$ in patients with type 2 diabetes [21,22]. Further, patients with type 2 diabetes tend to have higher TG and lower HDL-C values than dyslipidemic patients without type 2 diabetes [4]. TG levels are significantly higher and HDL-C levels significantly lower in patients with relatively poor glycemic control than in those with adequate control [21]. These findings confirm the importance of controlling both TG and HDL-C, in

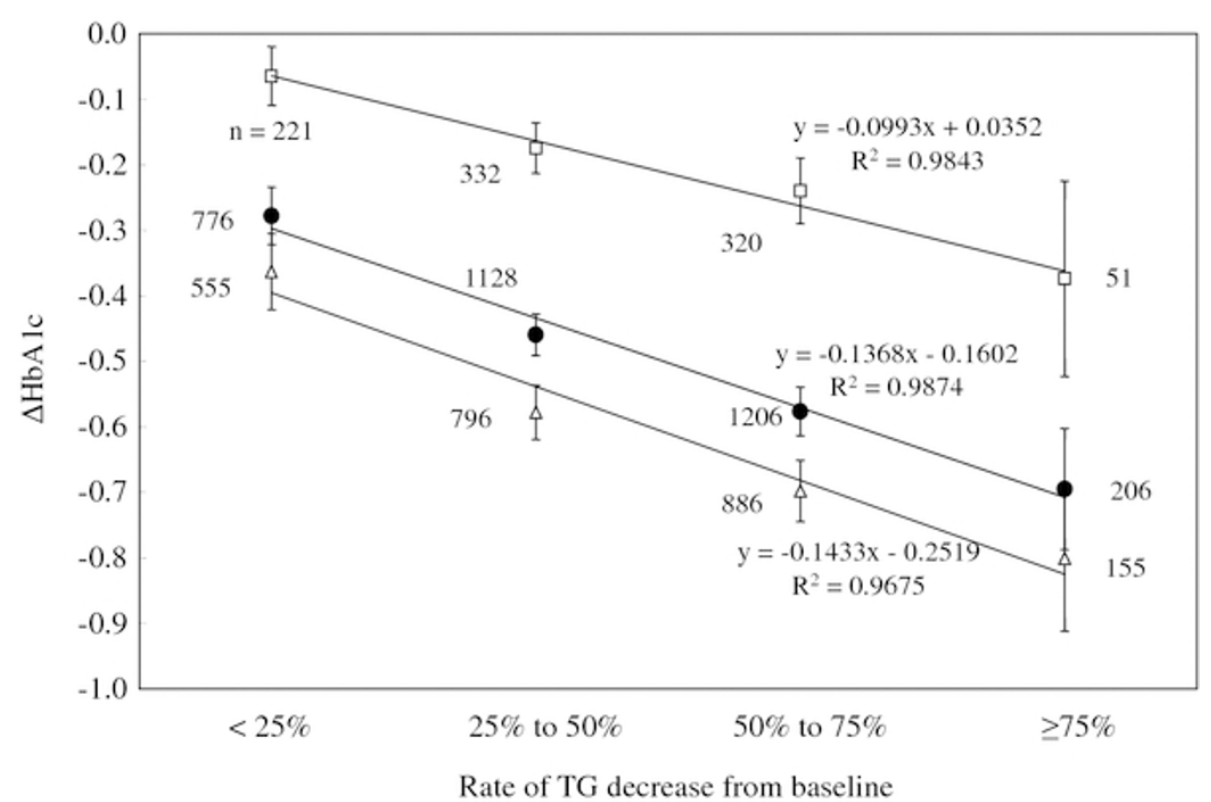

Figure 1 TG and HbA1c levels in patients depending on use of a diabetes drug. The graphs show the changes in HbA1c levels determined for all patients $(\cdot)$, patients taking a diabetes drug $(\boldsymbol{\Delta})$, and patients not taking a diabetes drug $(\square)$. 
Table 7 Adverse drug reactions in the safety analysis set

\begin{tabular}{cccc}
\hline Adverse drug reactions & Cases & Cases without diabetes drug & Cases with diabetes drug \\
\hline Number & 5978 & 2382 & 3596 \\
ADRs & $306(5.1 \%)$ & $103(4.3 \%)$ & $203(5.6 \%)$ \\
Blood creatine phosphokinase increased & $48(0.8 \%)$ & $17(0.7 \%)$ & $31(0.9 \%)$ \\
Blood creatinine increased & $46(0.8 \%)$ & $18(0.8 \%)$ & $28(0.8 \%)$ \\
Blood urea increased & $29(0.5 \%)$ & $10(0.4 \%)$ & $19(0.5 \%)$ \\
Renal impairment & $19(0.3 \%)$ & $8(0.3 \%)$ & $11(0.3 \%)$ \\
Aspartate aminotransferase increased & $18(0.3 \%)$ & $7(0.3 \%)$ & $11(0.3 \%)$ \\
Myalgia & $17(0.3 \%)$ & $6(0.3 \%)$ & $11(0.3 \%)$ \\
Hepatic function abnormal & $15(0.3 \%)$ & $2(0.1 \%)$ & $13(0.4 \%)$ \\
Pruritus & $13(0.2 \%)$ & $6(0.3 \%)$ & $7(0.2 \%)$ \\
Alanine aminotransferase increased & $13(0.2 \%)$ & $5(0.2 \%)$ & $8(0.2 \%)$ \\
Rash & $12(0.2 \%)$ & $6(0.3 \%)$ & $6(0.2 \%)$ \\
Dyspepsia & $7(0.1 \%)$ & $1(0.0 \%)$ & $6(0.2 \%)$ \\
Others & $72(1.2 \%)$ & $19(0.8 \%)$ & $53(1.5 \%)$ \\
\hline
\end{tabular}

addition to blood glucose, in the treatment of type 2 diabetes.

Statins have been widely used to treat dyslipidemia, and evidence supports their role in preventing cardiovascular events [23-26]. However, fibrates, including bezafibrate, generally have a stronger effect on TG and HDL-C than statins. Atorvastatin $20 \mathrm{mg} /$ day and rosuvastatin $10 \mathrm{mg} /$ day reduced TG levels by $4.6 \%$ and $36.4 \%$, and increased or decreased HDL-C levels by $4.5 \%$ and $2.0 \%$, respectively [27]. Although rosuvastatin (5-20 $\mathrm{mg}$ /day) decreased TG levels by $29 \%-31 \%$ and increased HDL-C levels by $12.4 \%-16.7 \%$, bezafibrate (400 mg/day) decreased TG levels by $45 \%$ and increased HDL-C levels by $43 \%$ [28]. The present study also revealed that bezafibrate decreased the rate of change in TG level by $45.4 \%$ and the rate of increase in HDL-C level by $14.0 \%$ (Table $3)$. These results suggest that the effect of fibrates on TG and HDL-C levels is stronger than that of statins.

Although controversial, evidence suggests that fibrates have a lower association with cardiovascular events than statins. Indeed, a recent meta-analysis of 18 fibrate trials [29] revealed that fibrates significantly reduce the risk of cardiovascular events, but not uniformly [30-34]. In the ACCORD study, cardiovascular disease risk in 5,581 patients [30] receiving combination therapy with a statin plus a fenofibrate was no different than that in patients with statin monotherapy. Further, in the BIP study of 3,090 patients [32], bezafibrate did not significantly reduce the primary endpoint (fatal or nonfatal myocardial infarction or sudden death).

Common findings between these studies [30-33] are as follows: first, baseline TG values were not high, averaging $1.8 \mathrm{mmol} / \mathrm{l}$ in ACCORD and $1.6 \mathrm{mmol} / \mathrm{l}$ in BIP. Second, subgroup analysis of patients with baseline TG values $\geq 2.2 \mathrm{mmol} / \mathrm{l}$ exhibited potent (31\%) risk reduction in ACCORD and 39.5\% $(P=0.02)$ in BIP. Results of the FIELD study were similar [34]. We therefore conclude that fibrates can play a prominent role in reducing the risk of cardiovascular events in patients with high TG levels. Further, recent reports indicate that statin therapy is associated with a slightly higher risk of developing diabetes $[35,36]$. These findings suggest that if a patient is at low risk for cardiovascular disease, the potential for statins to increase diabetes risk should be taken into account.

Bezafibrate reduces blood glucose levels in patients with type 2 diabetes $[14,15]$. Elkeles et al. reported that bezafibrate significantly decreased the combined incidence of ischemic change in ECG and documented myocardial infarction in patients with type 2 diabetes [37]. Further, Tenenbaum et al. reported that bezafibrate decreased the development and delayed the onset of type 2 diabetes in patients with impaired fasting glucose [38]. Therefore, bezafibrate may be more suitable than statins for treating dyslipidemic patients with type 2 diabetes if their cardiovascular risk is low. To our knowledge, our present study is the first to demonstrate the beneficial effects of bezafibrate on lipid and glucose metabolism in a large number of patients with diabetes.

Consistent with studies cited above, we showed here that bezafibrate improved blood glucose and lipid levels. All lipid values except LDL-C improved significantly from baseline, with TG, HDL-C levels and the TG/HDL ratio in particular showing significant changes. Further, HbA1c, FBG, and HOMA-R improved significantly from baseline. HbA1c levels decreased by $-0.47 \%$ in all patients and by $-0.76 \%$ in patients with baseline HbA1c levels $\geq 7.0 \%$. Notably, bezafibrate showed a potent hypoglycemic effect regardless of concurrent diabetes drug use. On analysis stratified by diabetes duration, bezafibrate alone reduced HbA1c in all subgroups, most notably in those with diabetes for $<1$ year. Therefore, 
bezafibrate monotherapy may be appropriate for treating early-onset type 2 diabetes coexisting with hypertriglyceridemia. Alternatively, hyperglycemic patients with inadequate blood glucose control might benefit from concomitant administration of bezafibrate and a diabetes drug.

We also demonstrated here that as TG levels decreased, those of HbA1c decreased by $0.47 \%$ in all patients (Figure 1 and Table 3). Ogawa reported that bezafibrate decreased TG levels by $50 \%$ and decreased HbA1c levels from $7.2 \%$ to $6.9 \%$ in patients with type 2 diabetes [16]. Taniguchi reported similar results [15]. In contrast, the three-year SENDCAP study of 164 patients with type 2 diabetes reported that while bezafibrate decreased TG significantly, the change in HbA1c levels over the course of the study was not significant between bezafibrate and the control groups [37]. Although longterm studies will be required to confirm this observation, average baseline TG levels were lower than those cited above, leading us to conclude that this may have caused the change in HbA1c levels.

Bays et al. reported the following two relationships between fatty acid levels and type 2 diabetes [39]: (1) chronically increased plasma free-fatty acid induces hepatic and muscle insulin resistance and impairs insulin secretion; and (2) enlarged fat cells become insulinresistant, with diminished capacity to store fat. When the storage capacity in adipocyte tissue is exceeded, lipids flow over into muscle and liver, causing muscle and hepatic insulin resistance. Bezafibrate has been reported to increase fatty acid degradation via beta-oxidation in the peroxisomes and mitochondria [40-42]. Further, Van der Ziji et al. reported that pancreatic fatty acid accumulation is related to $\beta$ cell dysfunction [43], and Fernandes-Santos et al. reported that bezafibrate prevented pancreatic fat accumulation and hypertrophy in mice while attenuating glucose intolerance and insulin resistance [44]. These studies suggest that plasma free fatty acid and ectopic fat accumulation involve glucose tolerance, and that bezafibrate improves glucose tolerance through fatty acid degradation via activating beta-oxidation.

ADRs were observed in 306 (5.1\%) of 5,978 patients in the safety analysis group. The most frequent were increases in blood levels of creatine phosphokinase $(0.8 \%)$, creatinine $(0.8 \%)$ and urea $(0.5 \%)$. No specific differences were observed related to the use or non-use of diabetes drugs. Betteridge and O' Bryan-Tear [45] and Beggs et al. [46] reported, respectively, that 7.7\% (7/ $91)$ and $5.4 \%(7 / 130)$ of ADRs were caused by bezafibrate administration. The rate of ADRs in the present study is comparable to their result.

In the present study, concurrent use of the biguanide drug metformin was $16.6 \%$. The guidelines of the
American Diabetes Association and the European Association for the Study of Diabetes recommend initial treatment of type 2 diabetes mellitus with metformin [47]. Since 2009, metformin treatment has been restricted to cases that do not respond to sulfonylureas. The maximum dose was $750 \mathrm{mg} /$ day, which, until 2010 in Japan at least, is much less than the dose administered in Western countries. Therefore, the results of clinical trials in Western countries cannot be directly applied to Japanese patients. Further, the majority of Japanese patients with type 2 diabetes mellitus are less obese and less insulin-resistant than European and American patients [48]. Currently in Japan, the maximum dose of metformin is $2,250 \mathrm{mg} /$ day.

Our study has several important limitations. First, it was conducted under a prospective observational cohort design with no control arm, and it was not possible to eliminate all confounding factors. Interpretation of our findings, therefore, requires caution until further studies with controls can be conducted. Second, changes in body weight, modification of lifestyle, and use of diabetes drugs were not recorded, and the effects of these variables on glucose metabolism cannot be ruled out. It is, however, important to note that other studies $[15,16]$ reported result similar to ours presented here. Moreover, of the 254 patients not treated with diabetes drugs in the present study, average HbA1c levels decreased by $0.56 \%$ after administration of bezafibrate (Table 4 ), strongly suggesting that bezafibrate alone lowers blood glucose levels. Third, for logistic, economic and other reasons, laboratory measurements could only be performed at each of the 1,066 institutions and not in a central laboratory. Although the JDS, in collaboration with the Japan Society of Clinical Chemistry, developed a national standardization scheme for determining HbA1c levels in 1995 in Japan [49], and Nihei et al. reported that commutability among the most frequently used analytical techniques in Japan was secured at a specific level [50], differences in HbA1c levels determined by different methods and laboratories cannot be ruled out. Nevertheless, we believe that the present results demonstrate convincingly the beneficial effects of bezafibrate in patients with type 2 diabetes in clinical settings.

\section{Conclusions}

This 24-week prospective observational study of dyslipidemic patients with diabetes or hyperglycemia showed that bezafibrate significantly reduced HbA1c levels as a function of baseline HbA1c level regardless of concurrent use of diabetes drugs. Further, a correlation was apparent between the rates of change of triglyceride and HbA1c levels. Patients with type 2 diabetes tended to have higher TG and lower HDL-C values [4]. We therefore conclude that the control of both TG and blood 
glucose levels is an important consideration in the treatment of dyslipidemia complicated by diabetes and that physicians should consider that bezafibrate is an effective therapy in these patients.

\begin{abstract}
Abbreviations
ADR: Adverse drug reaction; JDS: Japan Diabetes Society; FBG: Fasting blood glucose; HbA1c: Glycated hemoglobin; HDL-C: High-density lipoprotein cholesterol; HOMA-R: Homeostasis model assessment insulin resistance; LDLC: Low-density lipoprotein cholesterol; NGSP: National Glycohemoglobin Standardization Program; PPAR: Peroxisome proliferator-activated receptor; TC: Total cholesterol; TG: Triglyceride.
\end{abstract}

\section{Acknowledgements}

The authors express deep gratitude to the study participants and staff at the 1,066 institutions that provided the data for this study.

\section{Author details}

'Department of Internal Medicine, Teikyo University School of Medicine, 211-1 Kaga, Itabashi-ku, Tokyo, Japan. ${ }^{2}$ Department of Internal Medicine, Sakura Medical Center, Toho University School of Medicine, 564-1 Shimoshizu, Sakura-shi, Chiba, Japan. ${ }^{3}$ Department of Cardiovascular Medicine, Juntendo University, 2-1-1 Hongo, Bunkyo-ku, Tokyo, Japan. ${ }^{4}$ University of Tsukuba, 1-1-1 Tennodai, Tsukuba-shi, Ibaraki, Japan.

\section{Authors' contributions}

KS participated in drafting the manuscript. HD performed the statistical analysis. NY participated in the design of the study. $T$ conceived of the study and participated in its design and coordination and helped draft the manuscript. All authors read and approved the final manuscript.

\section{Competing interests}

This work was sponsored by KISSEl Pharmaceutical Company, Japan. $\pi$ is currently an active member of the GlaxoSmithKline KK scientific advisory board. TT has received research grants from Daiichi-Sankyo Co. Ltd., Astellas Pharma Inc., Kowa Co. Ltd., Shionogi Co. Ltd., Bayer Yakuhin Ltd. and Kissei Pharmaceutical Co. Ltd. KS has received research grants from Daichi Sankyo Co. Ltd., Astellas Pharma Inc., Ohtsuka Pharmaceutical Company, Kowa Co. Ltd., Kissei Pharmaceutical Co. Ltd., Banyu Pharmaceutical Co. Ltd. and Fukuda Denshi Co. Ltd. and has received honoraria as a lecturer from Kowa Co. Ltd., Daiichi Sankyo Co. Ltd., Sunny Health Co. Ltd., Takeda Pharmaceutical Co. Ltd., Fukuda Densi Co. Ltd., and Shionogi Pharmaceutical Co. Ltd. HD is an advisory member of Kowa Co. Ltd. and Sanofi-Aventis KK and has received honoraria for lectures and research grants from Kowa Co. Ltd., Pfizer Inc., Daiichi Sankyo Co. Ltd., AstraZeneca PLC, Astellas Pharma Inc., The Boston Scientific Corporation, Sanofi-aventis KK, Mochida Pharmaceutical Co. Ltd., Takeda Pharmaceutical Co. Ltd. and Dainippon Sumitomo Pharma Co. Ltd.

Received: 25 November 2011 Accepted: 23 March 2012 Published: 23 March 2012

\section{References}

1. Chan JC, Malik V, Jia W, et al: Diabetes in Asia: epidemiology, risk factors, and pathophysiology. JAMA 2009, 301:2129-2140.

2. Haffner SM, Lehto S, Rönnemaa T, et al: Mortality from coronary heart disease in subjects with type 2 diabetes and in nondiabetic subjects with and without prior myocardial infarction. N Engl J Med 1998, 339:229-234

3. Stratton IM, Adler Al, Neil HA, et al: Association of glycaemia with macrovascular and microvascular complications of type 2 diabetes (UKPDS 35): prospective observational study. BMJ 2000, 321:405-412

4. Uusitupa MI, Niskanen LK, Siitonen O, et al: 5-year incidence of atherosclerotic vascular disease in relation to general risk factors, insulin level, and abnormalities in lipoprotein composition in noninsulin dependent diabetic and non-diabetic subjects. Circulation 1990, 82:27-36.

5. Lehto S, Rönnemaa T, Haffner SM, et al: Dyslipidemia and hyperglycemia predict coronary heart disease events in middle-aged patients with NIDDM. Diabetes 1997, 46:1354-1359.
6. Wahl P, Hasslacher Ch, Lang PD, et al: Lipid-lowering effect of bezafibrate in patients with diabetes mellitus and hyperlipidaemia. Dtsch med Wochenschr 1978, 103:1233-1237.

7. Bruneder $\mathrm{H}$, Klein HJ: Treatment of hyperlipoproteinaemia in diabetic patients. Dtsch Med Wochenschr 1981, 106:1653-1656.

8. Tenenbaum A, Fisman EZ, Motro M, et al: Optimal management of combined dyslipidemia: what have we behind statins monotherapy? Adv Cardiol 2008, 45:127-153.

9. Krey G, Braissant O, L'Horset F, et al: Fatty acids, eicosanoids, and hypolipidemic agents identified as ligands of peroxisome proliferatoractivated receptors by coactivator-dependent receptor ligand assay. Mol Endocrinol 1997, 11:779-791.

10. Moya-Camarena SY, Van den Heuvel JP, Belury MA: Conjugated linoleic acid activates peroxisome proliferator-activated receptor alpha and beta subtypes but does not induce hepatic peroxisome proliferation in Sprague-Dawley rats. Biochim Biophys Acta 1999, 1436:331-342.

11. Peters JM, Aoyama T, Burns AM, et al: Bezafibrate is a dual ligand for PPAR alpha and PPAR beta: studies using null mice. Biochim Biophys Acta 2003, 1632:80-89.

12. Tenenbaum A, Motro M, Fisman E, Review Z: Dual and pan-peroxisome proliferator-activated receptors (PPAR) co-agonism: the bezafibrate lessons. Cardiovasc Diabetol 2005, 4:14-18.

13. Willson TM, Brown PJ, Sternbach DD, Henke BR: The PPARs: from orphan receptors to drug discovery. J Med Chem 2000, 43:527-550.

14. Jones $I R$, Swai $A$, Taylor $R$, et al: Lowering of plasma glucose concentrations with bezafibrate in patients with moderately controlled NIDDM. Diabetes Care 1990, 13:855-863.

15. Taniguchi A, Fukudhima M, Sakai M, et al: Effects of bezafibrate on insulin sensitivity and insulin secretion in non-obese Japanese type 2 diabetic patients. Metabolism 2001, 50:477-480.

16. Ogawa S, Takeuchi K, Sugimura K, et al: Bezafibrate reduces blood glucose in type 2 diabetes mellitus. Metabolism 2000, 49:331-334.

17. Elkeles R: Fibrates: old drugs with a new role in type 2 diabetes prevention? Br J Diabetes Vasc Dis 2011, 11:4-9.

18. Friedewald WT, Levy R, Fredrickson DS: Estimation of the concentration of low-density lipoprotein cholesterol in plasma, without use of the preparative ultracentrifuge. Clin Chem 1972, 18:499-502.

19. The Committee of Japan Diabetes Society on the diagnostic criteria of diabetes mellitus: Report of the Committee on the classification and diagnostic criteria of diabetes mellitus. J Jpn Diabetes Soc 2010, 53:450-467, in Japanese.

20. Hokanson JE, Austin MA: Plasma triglyceride level is a risk factor for cardiovascular disease independent of high-density lipoprotein cholesterol level: a meta-analysis of population-based prospective studies. J Cardiovasc Risk 1996, 3:213-219.

21. Khan HA, Sobki SH, Khan SA: Association between glycaemic control and serum lipids profile in type 2 diabetic patients: $\mathrm{HbA} 1 \mathrm{c}$ predicts dyslipidaemia. Clin Exp Med 2007, 7:24-29.

22. Zhang L, Qiao Q, Tuomilehto J, et al: Blood lipid levels in relation to glucose status in seven populations of Asian origin without a prior history of diabetes: the DECODA study. Diabetes Metab Res Rev 2009, 25:549-557.

23. Baigent C, Keech A, Kearney PM, et al: Efficacy and safety of cholesterollowering treatment: prospective meta-analysis of data from 90,056 participants in 14 randomised trials of statins. Lancet 2005, 366:1267-1278.

24. Mills EJ, Rachlis B, Wu P, Devereaux PJ, et al: Primary prevention of cardiovascular mortality and events with statin treatments: a network meta-analysis involving more than 65,000 patients. J Am Coll Cardiol 2008, 52:1769-1781.

25. Brugts JJ, Yetgin T, Hoeks SE, et al: The benefits of statins in people without established cardiovascular disease but with cardiovascular risk factors: meta-analysis of randomised controlled trials. BMJ 2009, 338 : b2376.

26. Baigent C, Blackwell L, Emberson J, et al: Efficacy and safety of more intensive lowering of LDL cholesterol: a meta-analysis of data from 170,000 participants in 26 randomised trials. Lancet 2010, 376:1670-1681.

27. Mazza F, Stefanutti C, Di Giacomo S, et al: Effects of low-dose atorvastatin and rosuvastatin on plasma lipid profiles: a long-term, randomized, open-label study in patients with primary hypercholesterolemia. Am J Cardiovasc Drugs 2008, 8:265-270. 
28. Saito $Y$, Yamada N, Shirai K, et al: Effect of rosuvastatin 5-20 mg on triglycerides and other lipid parameters in Japanese patients with hypertriglyceridemia. Atherosclerosis 2007, 194:505-511.

29. Jun M, Foote C, Lv J, et al: Effects of fibrates on cardiovascular outcomes: a systematic review and meta-analysis. Lancet 2010, 375:1875-1884.

30. ACCORD Study Group: Effects of combination lipid therapy in type 2 diabetes mellitus. N Engl J Med 2010, 362:1563-1574.

31. Tenenbaum A, Fisman EZ: "If it ain't broke, don't fix it": a commentary on the positive- negative results of the ACCORD Lipid study. CardiovasC Diabetol 2010, 9:24-28.

32. The BIP Study Group: Secondary prevention by raising HDL cholesterol and reducing triglycerides in patients with coronary artery disease: the Bezafibrate Infarction Prevention (BIP) study. Circulation 2000, 102:21-27.

33. The ACCORD Study Group: Effects of combination lipid therapy in type 2 diabetes mellitus. N Engl J Med 2010, 362:24-29, supplementary Appendix1. NEJM.org.

34. FIELD study investigators: Effects of long-term fenofibrate therapy on cardiovascular events in 9795 people with type 2 diabetes mellitus (the FIELD study): randomised controlled trial. Lancet 2005, 366:1849-1861.

35. Sattar N, Preiss D, Murray HM, et al: Statins and risk of incident diabetes: a collaborative meta-analysis of randomised statin trials. Lancet 2010, 375:735-742.

36. Rajapathak SN, Kumbhani DJ, Crandall J, et al: Statin therapy and risk of developing type 2 diabetes: a meta-analysis. Diabetes Care 2009, 32:1924-1929.

37. Elkeles RS, Diamond JR, Poulter $C$, et al: Cardiovascular outcomes in type 2 diabetes. A double-blind placebo-controlled study of bezafibrate: the St. Mary's, Ealing, Northwick Park Diabetes Cardiovascular Disease Prevention (SENDCAP) Study. Diabetes Care 1998, 21:641-648.

38. Tenenbaum A, Motro M, Fisman EZ, et al: Peroxisome proliferatoractivated receptor ligand bezafibrate for prevention of type 2 diabetes mellitus in patients with coronary artery disease. Circulation 2004, 109:2197-2202.

39. Bays H, Mandarino L, DeFronzo RA: Role of the adipocyte, free fatty acids, and ectopic fat in pathogenesis of type 2 diabetes mellitus: peroxisomal proliferator-activated receptor agonists provide a rational therapeutic approach: peroxisomal proliferator-activated receptor agonists provide a rational therapeutic approach. J Clin Endocrinol Metab 2004, 89:463-478.

40. Tremblay-Mercier J, Tessier D, Plourde M, et al: Bezafibrate mildly stimulates ketogenesis and fatty acid metabolism in hypertriglyceridemic subjects. J Pharmacol Exp Ther 2010, 334:341-346.

41. Cabrero A, Alegret M, Sánchez RM, et al: Bezafibrate reduces mRNA levels of adipocyte markers and increases fatty acid oxidation in primary culture of adipocytes. Diabetes 2001, 50:1883-1890.

42. Nagasawa $T$, Inada $Y$, Nakano $S$, et al: Effects of bezafibrate, PPAR panagonist, and GW501516, PPAR delta agonist, on development of steatohepatitis in mice fed a methionine- and choline-deficient diet. Eur J Pharmacol 2006, 536:182-191.

43. Van der Zijl NJ, Goossens GH, Moors CC, et al: Ectopic fat storage in the pancreas, liver, and abdominal fat depots: impact on $\beta$-cell function in individuals with impaired glucose metabolism. J Clin Endocrinol Metab 2011, 96:459-467.

44. Fernandes-Santos C, Evangelista Carneiro R, de Souza Mendonca L, et al: Rosiglitazone aggravates nonalcoholic Fatty pancreatic disease in C57BL/6 mice fed high-fat and high-sucrose diet. Pancreas 2009, 38 e80-e86.

45. Betteridge DJ, O'Bryan-Tear CG: Comparative efficacy and safety of ciprofibrate and sustained-release bezafibrate in patients with type II hyperlipidaemia. Postgrad Med J 1996, 72:739-743.

46. Beggs PW, Clark DW, Williams SM, et al: A comparison of the use, effectiveness and safety of bezafibrate, gemfibrozil and simvastatin in normal clinical practice using the New Zealand Intensive Medicines Monitoring Programme (IMMP). Br J Clin Pharmacol 1999, 47:99-104.

47. Nathan DM, Buse JB, Davidson MB, et al: Management of hyperglycemia in type 2 diabetes: a consensus algorithm for the initiation and adjustment of therapy: a consensus statement from the American Diabetes Association and the European Association for the Study of Diabetes. Diabetes Care 2006, 29:1963-1972.

48. Sone $H$, Ito $H$, Ohashi $Y$, et al: Obesity and type 2 diabetes in Japanese patients. Lancet 2003, 361:85
49. John WG, Mosca A, Weykamp C, et al: HbA1c standardisation: history, science and politics. Clin Biochem Rev 2007, 28:163-168.

50. Nihei T, Saitou T, Yokoyama T, et al: Evaluation for commutability of hemoglobin A1c measurement by IFCC calibration. JJCLA 2011, 36:18-25, in Japanese.

\section{doi:10.1186/1475-2840-11-29}

Cite this article as: Teramoto et al:: Effects of bezafibrate on lipid and glucose metabolism in dyslipidemic patients with diabetes: the JBENEFIT study. Cardiovascular Diabetology 2012 11:29.

\section{Submit your next manuscript to BioMed Central and take full advantage of:}

- Convenient online submission

- Thorough peer review

- No space constraints or color figure charges

- Immediate publication on acceptance

- Inclusion in PubMed, CAS, Scopus and Google Scholar

- Research which is freely available for redistribution

Submit your manuscript at www.biomedcentral.com/submit
C Biomed Central 